Goldschmidt 2021 Abstract

https://doi.org/10.7185/gold2021.7216

\section{Combining geochemistry with geochronology and hydromorphology to unravel human impacts in the Upper Rhine over the two last centuries}

\author{
CASSANDRA EUZEN ${ }^{1,2}$, LAURENT SCHMITT ${ }^{1}$, \\ VALENTIN CHARDON ${ }^{1}$, GILLES RIXHON ${ }^{3,4}$, THIERRY \\ PERRONE $^{2}$, FRANK PREUSSER $^{5}$, DOMINIQUE $^{2}$ \\ BADARIOTTI $^{1}$ AND FRANCOIS CHABAUX $^{2}$ \\ ${ }^{1}$ LIVE CNRS UMR 7362 University of Strasbourg ENGEES \\ ${ }^{2}$ ITES CNRS UMR 7063 Université de Strasbourg ENGEES \\ ${ }^{3}$ ENGEES École Nationale du Génie et de l'Eau et de \\ l'Environnement de Strasbourg \\ ${ }^{4}$ LIVE CNRS UMR 7362 University of Strasbourg \\ ${ }^{5}$ Institute of Earth and Environmental Sciences, University of \\ Freiburg
}

Presenting Author: cassandra.euzen@live-cnrs.unistra.fr

Assessing the effects of remediation measures to minimize impacts of human activities on the environment currently represents a major challenge for environmental scientists and policy-makers. Evaluating the effectiveness of measures undertaken in hydrosystems over the last decades to improve the chemical quality of river sediments is thus crucial. This, in turn, may strongly favour future efforts for ecological river restoration. Against this background, geochemical surveys are often based on a monitoring of the quality of both water and suspended matter at local measurement stations. However, similar approaches use dated sedimentary records, thereby offering the twofold advantage of (i) extending the temporal framework to past activities and (ii) considering several geomorphological units along and across the hydrosystem.

This study focuses on a $\sim 100 \mathrm{~km}$ long reach of the Upper Rhine hydrosystem, from Neuf-Brisach to Strasbourg (France). It aims at mapping the anthropogenic geochemical contamination recorded in fine sediments which deposited in response to several river engineering works. Fluvial deposition has varied both longitudinally in response to longitudinal adjustments and laterally because of the microtopography and historical infrastructures such as dikes. We thus first carried out an unprecedented hydromorphological reconstruction based on a planform study using ancient maps combined with information about the vertical evolution of the hydrosystem (flood record, water and groundwater levels, diachronic longitudinal profiles of the thalweg ...).

Based on this large geohistorical database, five sediment pits were dug and sampled. The depth-age model for each profile is based on a combination of luminescence and radiocarbon dating completed by geomorphological and hydrological information. These geochronological results coupled to mineralogical, grain size and geochemical characterization of the samples, especially metal concentrations, provide an accurate image of the evolution of the Rhine's sediment composition and quality over the last two centuries in the different geomorphological units. Results are also discussed in the light of the industrial development of the Rhine valley upstream of the studied reach. These results also allow discussing the hypothesis that paleo-channels cut by the Rhine's regulation and filled by fine sediments are major pollution hotspots in the hydrosystem in which pollutants have accumulated over time. 